\title{
An Improved Non-Regression Coefficients Method in Finding Sea Surface Temperature With a VHRR Data
}

Gin-Rong Liu

Professor (Liu), Graduate Student (Kuo), amd Ph.D. (Lin),Center for Space and Remote Sensing Research, National Central University, ChungLi, Taiwan 320.

Pao-Cheng Kao

Graduate Student, Institute of Atmospheric Science, National Central University, Chung-Li, Taiwan 320.

Tsung-Hua Kuo

Professor (Liu), Graduate Student (Kuo), amd Ph.D. (Lin),Center for Space and Remote Sensing Research, National Central University, ChungLi, Taiwan 320.

Tang-Huang Lin

Professor (Liu), Graduate Student (Kuo), amd Ph.D. (Lin),Center for Space and Remote Sensing Research, National Central University, ChungLi, Taiwan 320.

Chung-Chih Liu

Assistant Professor, Air Force Aeronautical and Technical School, Gang-Shan, Taiwan 820.

Follow this and additional works at: https://jmstt.ntou.edu.tw/journal

Part of the Engineering Commons

\section{Recommended Citation}

Liu, Gin-Rong; Kao, Pao-Cheng; Kuo, Tsung-Hua; Lin, Tang-Huang; and Liu, Chung-Chih (2001) "An Improved NonRegression Coefficients Method in Finding Sea Surface Temperature With a VHRR Data," Journal of Marine Science and Technology. Vol. 9: Iss. 2, Article 10.

DOI: $10.51400 / 2709-6998.2445$

Available at: https://jmstt.ntou.edu.tw/journal/vol9/iss2/10

This Research Article is brought to you for free and open access by Journal of Marine Science and Technology. It has been accepted for inclusion in Journal of Marine Science and Technology by an authorized editor of Journal of Marine Science and Technology. 


\section{An Improved Non-Regression Coefficients Method in Finding Sea Surface Temperature With a VHRR Data}

\section{Acknowledgements}

This work was made possible by a grant from the National Science Council of ROC. The grant number were NSC-84-2111-M-008-035 and NSC89-2111-M008- 024-AP6. The authors want to thank Mr. Charlie C. $\mathrm{K}$. Liang for his kindness to reviewing this English writing. 


\title{
AN IMPROVED NON-REGRESSION- COEFFICIENTS METHOD IN FINDING SEA SURFACE TEMPERATURE WITH AVHRR DATA
}

\author{
Gin-Rong Liu*, Pao-Cheng Kao**, Tsung-Hua Kuo*, \\ Tang-Huang Lin* and Chung-Chih Liu***
}

Keywords: sea surface temperature (SST), NOAA AVHRR, remote sensing.

\section{ABSTRACT}

$\mathrm{Yu}$ and Barton proposed a non-regression-coefficient method in improving the accuracy of routine sea surface temperature retrievals through satellite data, which are then applied to sea surface temperature estimation models such as MCSST or CPSST algorithms. Their method involves a parameter called $R_{54}\left(=\Delta T_{5} / \Delta T_{4}\right)$, which is derived from the ratio of neighborhood temperature variances from two window channels in the thermal IR region. Due to the fact that statistical calculations were used in the derivation for the value of $R_{54}$, the method is not applicable in various real cases. The aim of this study is to retain the advantage of their method in terms of its physical considerations and derivations, while providing an alternative in improving the calculations of $R_{54}$. In this study, a spatial coherence method is also used to mask cloudy areas, and an improved three-point method was brought in to determine the clear-sky brightness temperature. A NOAA-12 AVHRR data set partially covered with clouds was used to estimate a $10^{0} \times 10^{0}$ longitude-latitude SST map of the Taiwan area, which were compared with 61 ship-measured SSTs, as well as SST retrievals estimated by Chen, MCSST and CPSST. The results reveal improvements in the $0.8 \mathrm{~K}$ RMSE and $0.1 \mathrm{~K}$ bias SST map. The accuracy levels also grew higher, especially for partially cloud-contaminated cases. Moreover, this study can further produce maps regarding the amount of clouds present, or the temperature distribution of the cloud-tops for related research.

\section{INTRODUCTION}

Sea surface temperature (SST) is a very important parameter in meteorology and oceanography. SST data are necessary in many related research topics. For example, meteorologists can forecast changes in the

Paper Received July 10, 2001. Author for Correspondence: Gin-Rong Liu. * Professor (Liu), Graduate Student (Kuo), amd Ph.D. (Lin),Center for Space and Remote Sensing Research, National Central University, ChungLi, Taiwan 320.

**Graduate Student, Institute of Atmospheric Science, National Central University, Chung-Li, Taiwan 320.

***Assistant Professor, Air Force Aeronautical and Technical School, Gang-Shan, Taiwan 820 atmospheric circulation by monitoring SST anomalies, such as El Nino, which significantly influences the global climate. This can be observed via satellite data during their initial stages by detection of abnormal SST warming in the South Pacific Ocean. SST maps can also provide information to the fishing industry. For example, the mullet fishing ground was generally formed at the front boundary of $20 \sim 22^{\circ} \mathrm{C}$ as the isothern paralleled to the costal line.

Various techniques and theorems for estimating SSTs have been raised ever since the late 1960s (Curtis and Rao, 1969). Smith et al. (1970) derived a statistical histogram method to assess SST values from data in clear sky conditions. Afterwards, some researchers focused on multi-window techniques for atmospheric correction to produce more accurate SST maps (Anding and Kauth, 1972; Maul and Sidran, 1972). Throughout the years, many efforts were made in improving the SST estimation, and results clearly showed that through satellite remote sensing, the accuracy could reach about 1.0K RMSE (Prabhakara et at., 1974; Chedin et at., 1981; Chen, 1986). The U.S. National Environment Satellite Data and Information Service (NESDIS) adopted the Multi-channel Sea Surface Temperature (MCSST) algorithm (McClain, 1980) in estimating the global SST from NOAA AVHRR data. In 1988, Walton proposed a non-linear SST algorithm called the Cross Product Sea Surface Temperature (CPSST) for the estimation of the global SST. Generally, the method was similar to MCSST, which both employed a regression method in obtaining their respective coefficients. Yet, his study showed that the CPSST could be more accurate than the MCSST in some extreme weather conditions.

Hagan (1994) pointed out that SST estimations from satellite data were primarily influenced by three factors: the upwelling sea surface radiation flux, water vapor, and the vertical atmospheric temperature/humidity profiles. In other words, algorithms which do not correct the atmospheric factors properly, cannot accu- 
rately retrieve a SST map. Therefore, based on the radiative transfer equation (RTE), Yu and Barton (1994) derived a parameter, $R_{54}$, to overcome this difficulty by using data from two window channels in the thermal IR region. However, their algorithm was basically restricted to clear-sky cases only. Our study shows that the algorithm induces some unreasonable $R_{54}$ values for pixels that are adjacent to the cloud boundary. In other words, SST estimation by their method would produce unreasonable SST values in clear-sky areas that are in the vicinity of cloud pixels. Therefore, one of our study's goals is to retain the method's physical aspects, while improving the accuracy of the calculation of $R_{54}$. We will also show additional schemes in reducing the SST estimation error. For example, the spatial coherence method and an improved three-point method will be used to determine the brightness temperature for the clear-sky area. Finally, a $10^{0} \times 10^{0}$ longitude-latitude SST map of the Taiwan area will be produced. The accuracy of our algorithm study will be confirmed by comparing our results to other researches.

\section{METHODOLOGY}

\section{Calculation of $R_{54}$}

The MCSST algorithm can be expressed as

$$
T_{s}=\alpha_{0}+\alpha_{1} T_{i}+\gamma\left(T_{i}-T_{j}\right)
$$

where $T_{s}$ is the estimated SST, and $T_{i}$ and $T_{j}$ are the brightness temperatures for the two thermal IR window channels, respectively. If the AVHRR data are applied, $T_{i}$ and $T_{j}$ refer to the brightness temperature of AVHRR channels 4 and 5, and $\alpha_{0}, \alpha_{1}$ and $\gamma$ are the regression coefficients. Mathematically, the CPSST method has the same function form as MCSST, except for the $\gamma$ value. The $\gamma$ of CPSST can be expressed as

$$
\gamma=\frac{a_{0}+a_{1} T_{j}}{b_{0}+b_{1} T_{i}+b_{2} T_{j}}
$$

where $T_{i}$ and $T_{j}$ are the brightness temperatures at two different wavelengths in the infrared window region, and $a_{0}, a_{1}, b_{1}$ and $b_{2}$ are the regression coefficients. Basically, the existing atmospheric effect at these two channels did not show a significant difference, but still contribution some difference in radiance observations.

Unlike the MCSST and CPSST methods, the algorithm of Yu and Barton (1994) can be written as follows

$$
T_{s}=T_{0}=T_{j}+\frac{C_{i}\left(T_{i}\right)}{C_{i}\left(T_{i}\right)-R_{j i} C_{j}\left(T_{j}\right)}\left(T_{i}-T_{j}\right)
$$

where $C_{i}$ and $C_{j}$ are equal to

$$
C(T)=\frac{c_{2}^{\prime}}{T^{2}} \frac{e^{c_{2}^{\prime} 2 / T}}{e^{c_{2}^{\prime} 2 / T-1}}-\frac{2}{T}
$$

where $c_{2}^{\prime}=v c_{2}$, and $v$ is the observation frequency and $c_{2}$ is a constant equaling $1.438833 \mathrm{~K}-\mathrm{cm}$.

For AVHRR data, $R_{j i}$ is equal to $R_{54}$, and can be calculated through a statistical method

$$
R_{54}=\frac{\Delta T_{5}}{\Delta T_{4}}=\sum_{S}\left(\frac{T_{5}(n)-\bar{T}_{5}}{T_{4}(n)-\bar{T}_{4}}\right) / N
$$

where the selected s is equal to $D / 2 \leq\left|T_{4}(n)-\bar{T}_{4} \leq\right|$ $2 D, D$ is the variance of $\Delta T_{4}$ in the window, and $N$ is the selected number of pixels. In the study of $\mathrm{Yu}$ and Barton (1994), a selected window area of $50 \times 50$ pixels was used. In most general cases, the neighborhood temperature variances and the variance of $\Delta T_{4}$ in a single area are both small. Thus, the values of $R_{54}$ become unreasonable when the selected area does not have a sufficient number of clear-sky pixels. In such a situation, their method would fail for some pixels, especially in partially cloudy areas. In order to improve their algorithm, a modification of the derivation of $R_{54}$ must be made.

Generally, the emissivity, $\varepsilon_{4}$ and $\varepsilon_{5}$, of the sea surface in the thermal infrared region (AVHRR channel 4 and 5) is very high and uniform, rendering it to be seen as a blackbody, i.e. $\varepsilon_{4}=\varepsilon_{5}=1.0$ (Dalu, 1985). Hence, $R_{54}$ can be simplified as

$$
R_{54} \cong \frac{\Delta T_{5}}{\Delta T_{4}}
$$

The simplification of $R_{54}$ will be examined later to understand its validation.

\section{Cloud filtering}

In our study we derive a $0.5^{\circ} \times 0.5^{\circ}$ longitudelatitude SST map from AVHRR data. In other words, our procedure will use $50 \times 50$ pixels of AVHRR data to determine one specific SST value. In order to correctly distinguish the clear sky area from the cloudy area, the spatial coherence method will be applied (Coakley and Bretherton, 1982). Generally, the radiation flux over a cloudy area will vary tremendously, even for a very small size. On the other hand, the flux over the sea surface varies slightly. Based on this aspect, by first calculating the local mean and standard deviation for every $2 \times 2$ pixel window and examining the values, we can classify the windows into three types: clear, partly cloudy and completely cloudy areas. In terms of statistical properties, the clear sky area has a high brightness temperature mean and a low standard deviation. The cloudy area has a low brightness temperature mean and a low standard deviation. The partially cloudy area has 
a median mean and a high standard deviation. The brightness temperature histogram for a cloud-contaminated area appears as a two-peak distribution. By employing the spatial coherence method, these partially cloudy pixels can be spotted and thrown away.

\section{Determination of the mean brightness temperature}

Although the mean SST can be roughly estimated from the previous histogram, a more accurate method, the three-point method, was also used to derive the SST values. The advantage of this method is that we do not need to know the maximum frequency $\left(f_{0}\right)$ and the standard deviation $\left(\sigma_{0}\right)$ beforehand. We assume that the SST histogram has a normal distribution pattern, and we choose any three points we prefer on the right wing of the histogram. After inserting the temperatures $\left(x_{i}\right)$ and frequencies $\left(f\left(x_{i}\right)\right)$ of the three points into the normal distribution, we obtain:

$$
f\left(x_{i}\right)=f_{0} \exp \left(\frac{-\left(x_{i}-x_{0}\right)^{2}}{2 \sigma_{0}^{2}}\right) \quad i=1,2 \text { and } 3
$$

where $x_{0}$ is the mean temperature and can be derived by the equation.

\section{DATA}

We use the data of AVHRR channels 4 and 5 for testing because the two channels are the so-called splitwindows. Generally speaking, the two windows are barely influenced by atmospheric gases, except for water vapor. As the influence of water vapor on the two channels is different, this makes it possible to take advantage of this aspect by estimating and correcting the water vapor effect.

The data used in this study are NOAA AVHRR data, and was acquired and processed by the Meteorological Satellite Laboratory, Center for Space and Remote Sensing Research (CSRSR), National Central University (NCU). The ship-measured SST data were taken within 3 hours of the NOAA satellite pass. Taking into account the data concurrence of ship-measured data and the results conducted by Chen (1986), MCSST and CPSST, the NOAA-12 and radiosonde data collected during 1994 to 1995 were chosen in this study. Radiosonde data were utilized in the simulation, while the ship-measured SST was used to examine the estimated SST. Both sets of data came from the Central Weather Bureau, Taiwan, ROC, and had already underwent error checking. The ship-measured SST dated from July 1994 to May 1995 , covered an area from $117^{\circ} \mathrm{E}$ to $135^{\circ} \mathrm{W}$, $19^{\circ} \mathrm{N}$ to $43^{\circ} \mathrm{N}$. Because the ship-measured SST and the radiosonde data were taken individually, it was difficult in coinciding the ship-SST and radiosonde readings to exactly the same temporal and spatial parameters. Therefore, radiosonde data having a ship-measured SST within three hours from an area of $0.5^{\circ} \times 0.5^{\circ}$ longitudelatitude and were used. Generally, the other methods Chen, MCSST and CPSST, we compared have a similar methodology. All of them used the regression equation to construct the relationships between SST truth and the satellite-observed brightness temperatures. Basically, the regression coefficients were related to the sampling time, areas and methods.

\section{SIMULATION AND ANALYSIS}

We used 363 radiosonde data, ship-measured SSTs and a Lowtran-7 model (Kneizys et al., 1988) to simulate the atmospheric transmittance and brightness temperatures observed by NOAA-12 AVHRR channels 4 and 5. By investigating these simulated data of the transmittance ratio between channels 4 and 5, we can thus evaluate and correct the SST estimated algorithm.

First, we calculated the $R_{54}$ value from equation 6 from the simulated atmospheric transmittances from AVHRR channels 4 and 5. The comparison is shown in Figure 1 and can be expressed as follows:

$$
\begin{aligned}
& R_{54}(\text { by } \mathrm{Yu} \text { and Barton }) \\
& =1.0217 \times\left(\frac{\tau_{5}}{\tau_{4}}\right)-0.0171732
\end{aligned}
$$

where $\tau_{4}$ and $\tau_{5}$ are the atmospheric transmittance at

$$
\text { R54 }(\text { real })=1.02172^{\star}(\text { Tau5/Tau4 })-0.0171732
$$

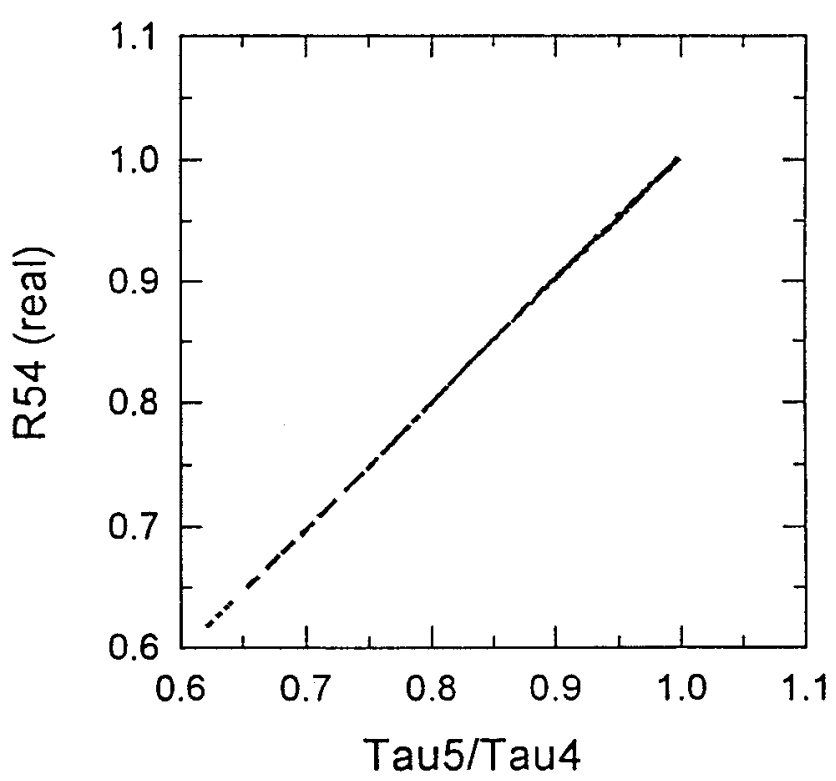

Fig. 1. A comparison of $\tau_{5} / \tau_{4}$ and $R_{54}$ simulated from 363 radiosonde data sets. 
AVHRR channels 4 and 5, respectively. This result confirmed what we had pointed out earlier: $R_{54}$ can be approximated by $\left(\tau_{5} / \tau_{4}\right)$. For the AVHRR window channels 4 and 5, the main absorbing gas is water vapor, and the water vapor difference between the two channels can be seen as a indicator of the water vapor amount, meaning that the atmospheric transmittance is a exponential function of $\left(T_{4}-T_{5}\right)$. The simulated transmittance and $\left(T_{4}-T_{5}\right)$ relationships are shown in Figure 2 and 3, respectively, and may be regressed further as follows

$$
\tau_{4}=1.06722 \cdot \exp \left[-0.474998 \cdot\left(T_{4}-T_{5}\right)\right]
$$

and

$$
\tau_{5}=1.14725 \cdot \exp \left[-0.474998 \cdot\left(T_{4}-T_{5}\right)\right]
$$

We replaced $R_{54}$ with $\left(\tau_{5} / \tau_{4}\right)$ and estimated $T_{s}$ by Equation (2). A comparison of the estimated $T_{s}$ with the ship-measured SST showed that one systematic bias existed (Figure 4). The retrieved error, $\Delta T_{s}$, can be derived by the error of $\Delta R_{54}$,

$$
\begin{aligned}
\Delta T_{s} & =\frac{1}{\left(c_{4}-R_{54} c_{5}\right)}\left[c_{5} \omega_{4}-c_{4} \omega_{5}\right. \\
& \left.+c_{4} \omega_{5}\left(T_{4}-T_{5}\right)\right] \Delta R_{54},
\end{aligned}
$$

\section{Tau4 $=1.06722^{\star} \exp \left(-0.328839^{\star}(T b 4-T b 5)\right)$}

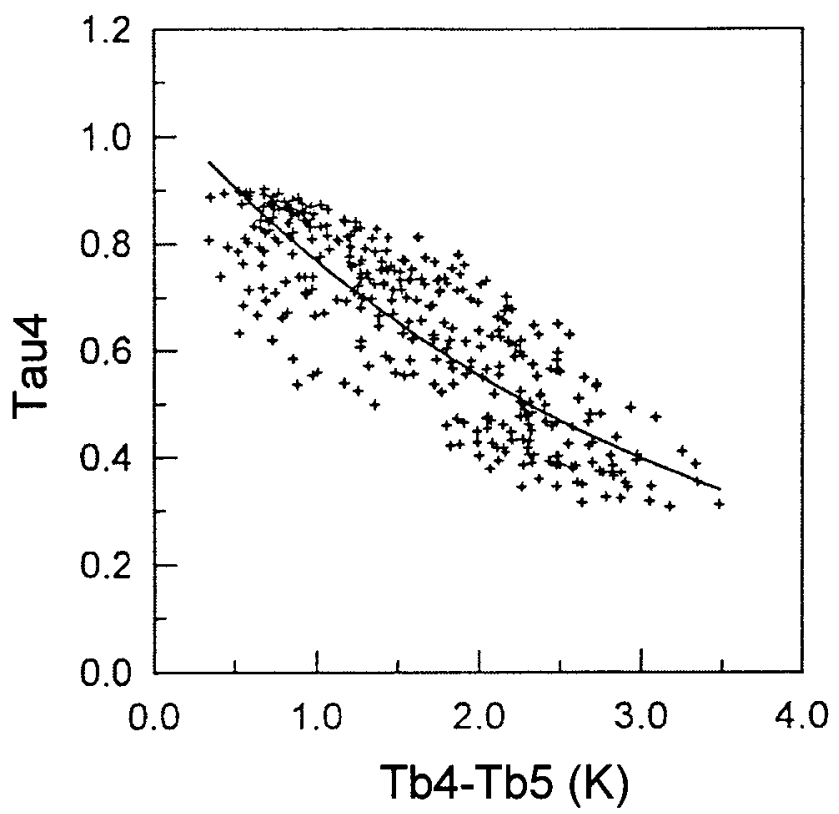

Fig. 2. A comparison of AVHRR channel 4 transmittance and $\left(T_{4}-T_{5}\right)$. The transmittance of channel 4 was simulated from 363 radiosonde data sets.

$$
\omega_{i}=\frac{1}{\varepsilon_{i}(v) \tau_{i}(v)} \quad i=4 \text { and } 5
$$

because

$$
\begin{aligned}
& R_{54} \cong \frac{\tau_{5}}{\tau_{4}} \propto \exp \left(T_{4}-T_{5}\right) \cong \sum a_{n}\left(T_{4}-T_{5}\right)^{n} \\
& n=1,2,3 \ldots
\end{aligned}
$$

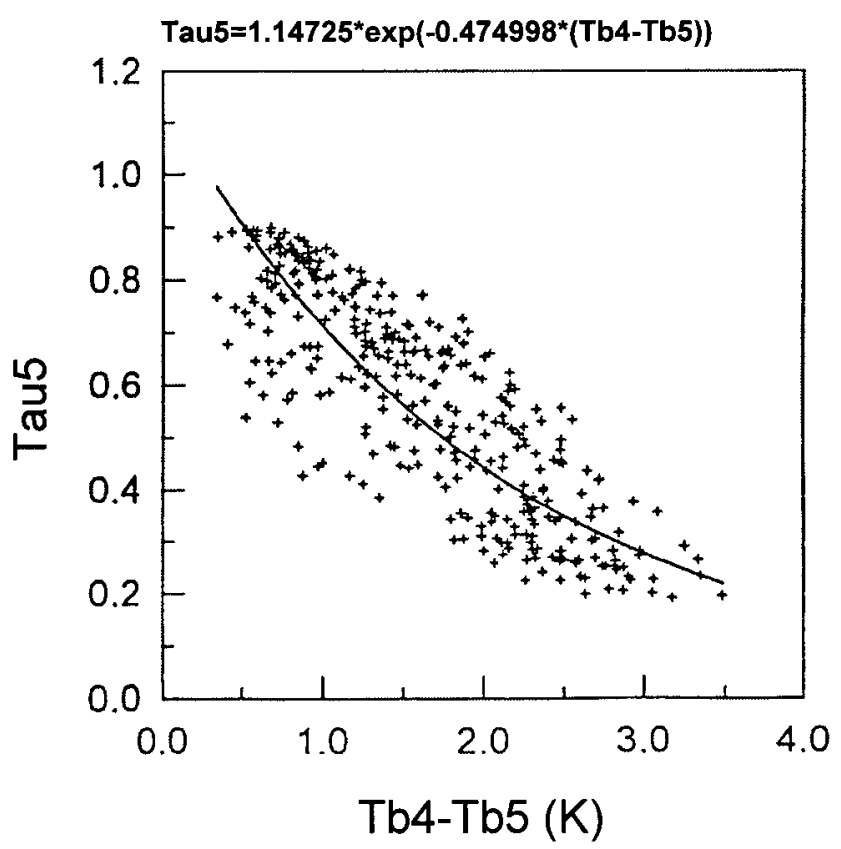

Fig. 3. Same as Figure 2, except for channel 5.

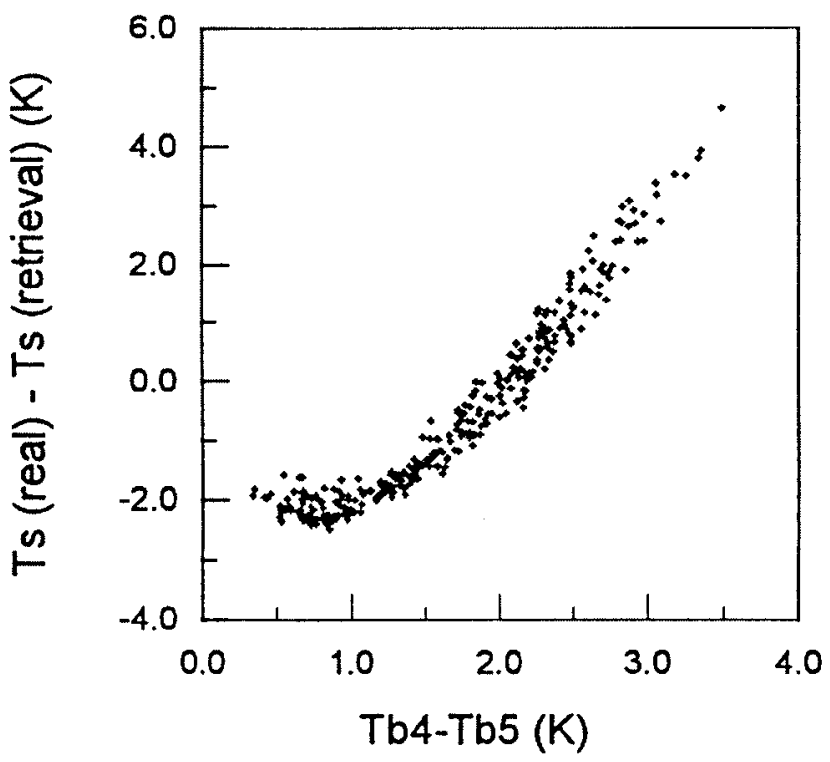

Fig. 4. A comparison of the difference of ship-measured SST and retrieved SST and $\left(T_{4}-T_{5}\right)$. 
where $c_{4}$ and $c_{5}$ are coefficients, $\varepsilon(v)$ is the surface emissivity at the frequency of $v$. Also, $\tau$ is the atmospheric transmittance. The bias is a polynomial function of $\left(T_{4}-T_{5}\right)$. Thus, we can correct the systematic error by adding one polynomial function of $\left(T_{4}-T_{5}\right)$. As the retrieved result's accuracy would be influenced by the radiometer instrument noise in real AVHRR data, the polynomial function order can not be chosen too high. In addition, higher order did not show lesser physical meaning. Generally, the lower order of polynomial is the best choice even it has slight higher error. In this study, the 2 nd to 5 th orders were tested.

\section{RESULT AND DISCUSSION}

A $10^{\circ} \times 10^{\circ}$ area in a NOAA-12 image (path \#20999) of the Taiwan area, acquired on May 31, 1995, was tested to derive the $R_{54}$ values, in order to compare our result to the performance of other studies. Both methods in this study and the one of Yu and Barton's were processed. Figure 5 shows that our method can compute the value of $R_{54}$ for the entire image, except for the upper one. We found that the upper image was cloudy. On the other hand, the $R_{54}$ map derived by $\mathrm{Yu}$ and Barton's method (1994) showed some unreasonable values around the outer parts of the cloudy areas (Figure 6). Comparisons of $R_{54}$ from other satellite data also reveal this aspect and prove our $R_{54}$ approximation computation to be valid.

Our simulation shows that the estimated SST must be corrected by a polynomial function. The regression

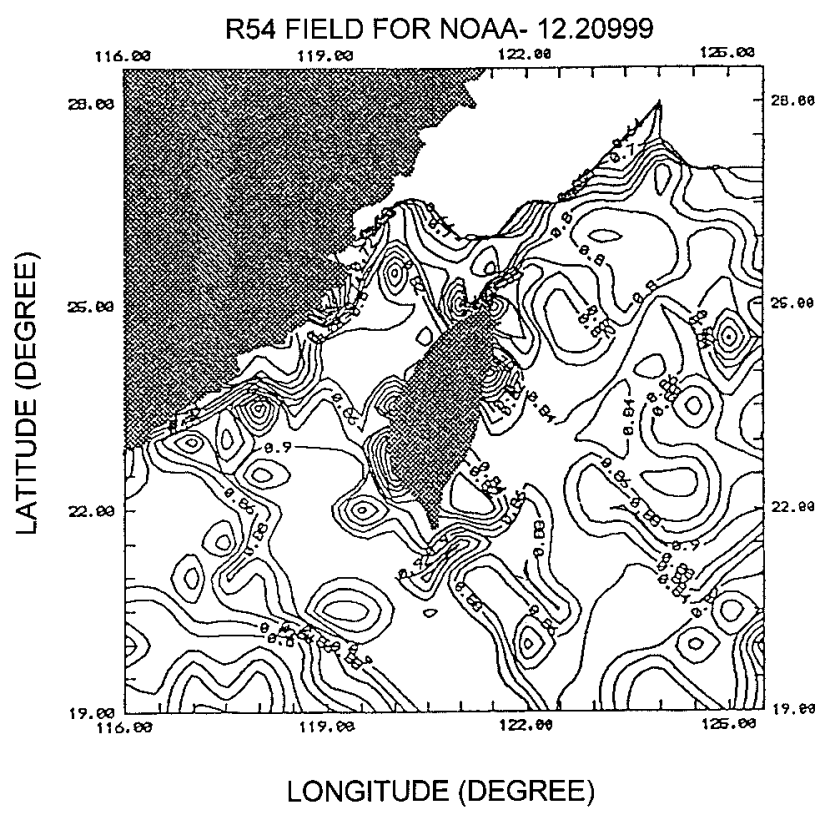

Fig. 5. The $R_{54}$ map derived by this study with NOAA AVHRR data acquired on May 31, 1995. result for four different orders was compared (Table 1). As discussed previously, an order that is too high will not produce better corrections because of the instrument noise inherent in AVHRR data. The comparison of the RMSE and the bias showed that the 3rd order of the polynomial would serve as the best correction for this study.

We applied our SST estimation to real AVHRR data, comparing it (indicated with 'Liu') to the shipmeasured SST and SSTs measured by Chen (1986), CPSST and MCSST (Table 2, Figures 7 to 10), respectively. Their RMSE and bias are also shown in these figures. The tested area was the same as the previous analysis area. The results showed that our method obtained a $0.8 \mathrm{~K}$ RMSE and $0.1 \mathrm{~K}$ bias SST map, establishing the fact that our results are more accurate than the ones estimated by other algorithms.

Not only does the method produce better results, it can also derive useful by-products, such as the temperature over the cloud-tops and the amount of clouds in a map. Basically, the derivation of the temperature over

Table 1. The RMSE and bias for polynomial functions for systematic error reduction. The tested orders are from 2 to 5

\begin{tabular}{ccc}
\hline Orders & RMS & bias \\
\hline 2 & 0.7972 & 0.0969 \\
3 & 0.7963 & 0.0964 \\
4 & 0.7966 & 0.0975 \\
5 & 0.7968 & 0.0970 \\
\hline
\end{tabular}

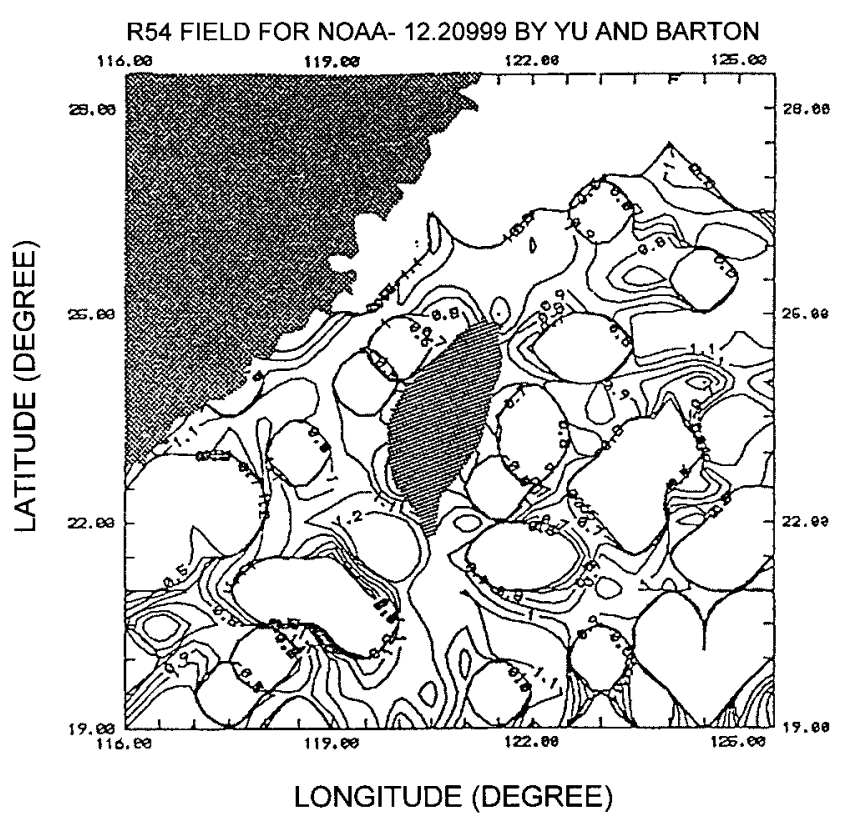

Fig. 6. Same as Figure 5, except by Yu and Barton's method (1994). 
Table 2. Polynomial functions of Chen, MCSST and CPSST used in this study compared to our result

\begin{tabular}{cl}
\hline Methods & Algorithms \\
\hline Chen $(1986)$ & SST $=-3.7383+3.8275 \times \mathrm{Tb} 4-2.8122 \times \mathrm{Tb} 5$ \\
MCSST & $\mathrm{SST}=-10.05+1.0346 \times \mathrm{Tb} 4+2.58 \times(\mathrm{Tb} 4-\mathrm{Tb} 5)$ \\
CPSST & $\mathrm{SST}=[(0.1761 \times \mathrm{Tb} 5-47.56) /(0.1761 \times \mathrm{Tb} 5-0.117 \times \mathrm{Tb} 4-15.72)] \times(\mathrm{Tb} 4-\mathrm{Tb} 5+0.2)+\mathrm{Tb} 4$ \\
\hline
\end{tabular}

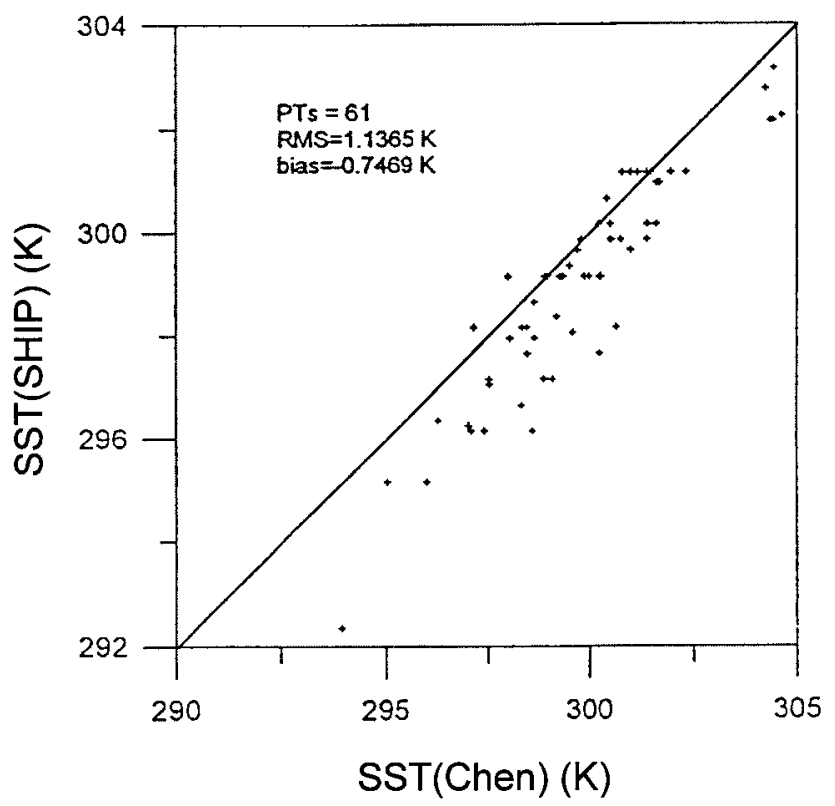

Fig. 7. A comparison of SST estimated by Chen (1986) and from shipmeasurements.

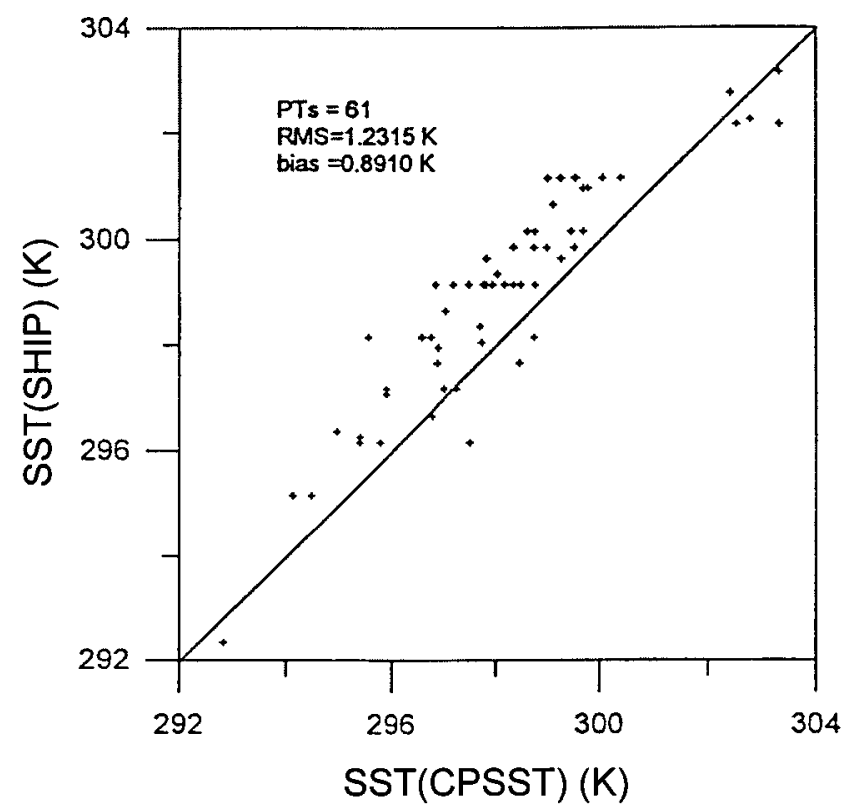

Fig. 8. A comparison of SST estimated by CPSST and from shipmeasurements.

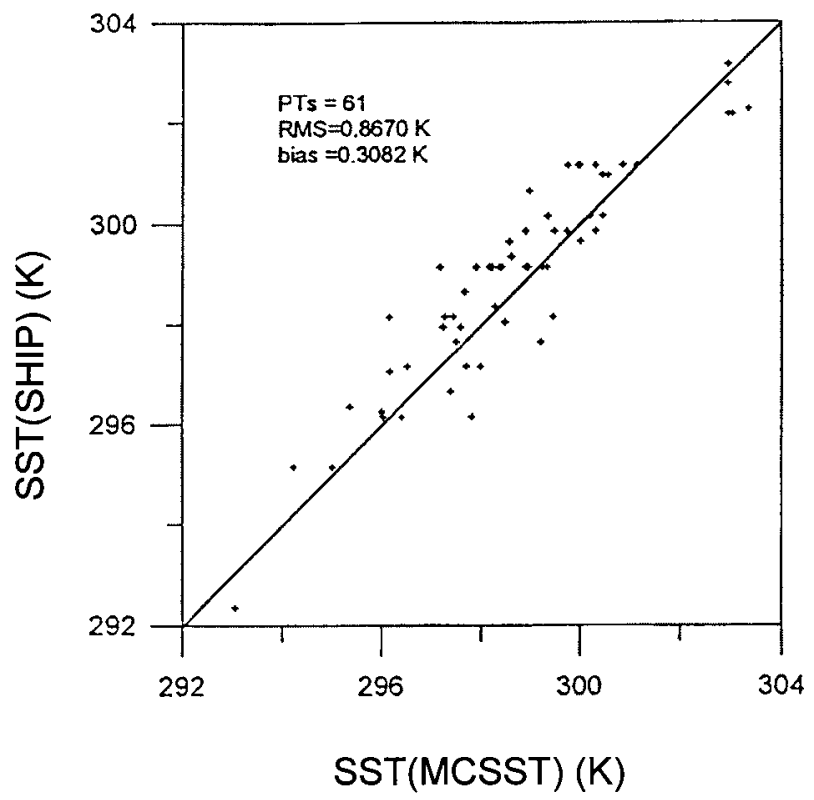

Fig. 9. A comparison of SST estimated by MCSST and from shipmeasurements.

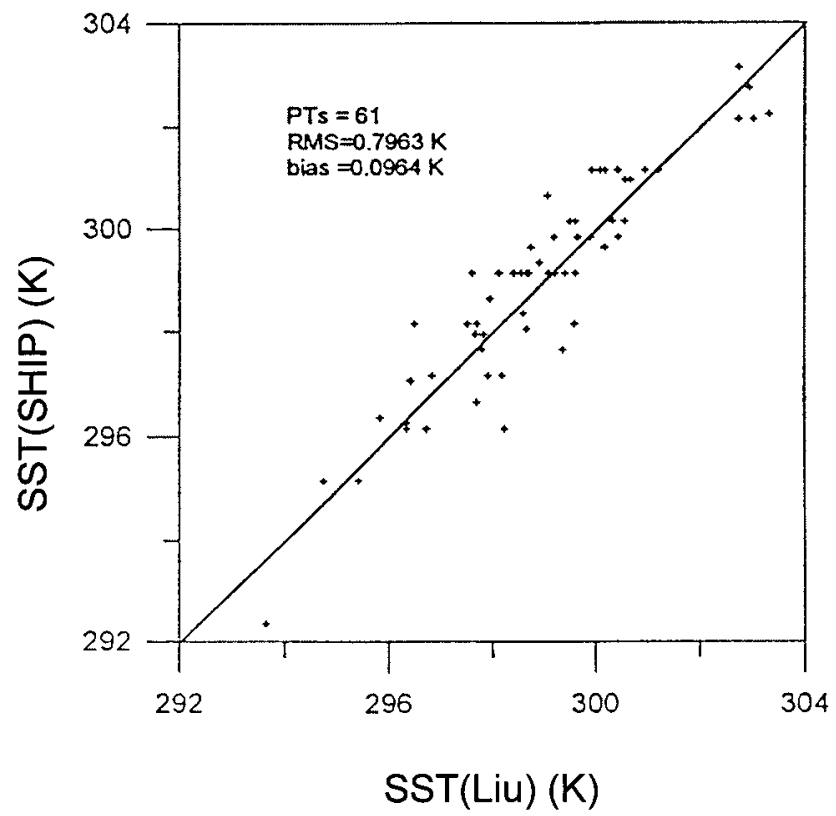

Fig. 10. A comparison of SST estimated with our improved method and from ship-measurements. 
the cloud-tops is the same as the derivation of the SST, but with the addition of some processes, because the cloudy area histograms are not ideally normally distributed. If only three sampling points are used to fit the normal distribution of the brightness temperature cloudy pixels, a higher error would be induced. Therefore, we pick 9 points in random and discard the points with a frequency near zero. We then compute the mean and standard deviations for any three points chosen from the previous 9 points. Finally, we obtain 84 sets of mean and standard deviations and use them to obtain a new histogram. The peak of this new histogram is the temperature over the cloud-tops, and can be further used to assess the amount present.

\section{CONCLUSION}

The improvements show that our method can remove unreasonable $R_{54}$ values that appear in $\mathrm{Yu}$ and Barton's method (1994). Further comparisons also show that we obtain better SST results. Moreover, a systematic error that would appear in the SST estimation can be corrected by a 3rd order polynomial. Overall, the improvements proposed in this study are practical for real operational work because they can be more easily and quickly processed for local areas as well as for different climate conditions while keeping the physical meaning of their method.

\section{ACKNOWLEDGMENTS}

This work was made possible by a grant from the National Science Council of ROC. The grant number were NSC-84-2111-M-008-035 and NSC89-2111-M008- 024-AP6. The authors want to thank Mr. Charlie C. K. Liang for his kindness to reviewing this English writing.

\section{REFERENCES}

1. Anding, D., and Kauth, R., 1972, Estimation of sea surface temperature from space. Remote Sensing of Environment, 1, 217-220.

2. Curtis, W. R., William, R., and Rao, P. K., 1969, Gulf stream thermal gradiants from satellite, ship and aircraft obsrvations. Journal of Geophysics Research, 74, 69846990.

3. Chedin, A., Scott, N. A., and Berroir, A., 1981, A singlechannel, double determination from coincident
METEOSAT and TIROS-N radiometric measurement. Journal of Applied Meteorology, 1, 613-618.

4. Chen, W. J., 1986, Estimation of SST with Meteorological Satellite Data. Thesis, National Taiwan University, Taipei, Taiwan.

5. Dalu, G., 1985, Emittance effect on the remotely-sensed sea surface temperature. International Journal of Remote Sensing, 6, 733-740.

6. Deschamps, P. Y., and Phulpin, T., 1980, Atmospheric correction of infrared measurements of sea surface temperature using channels at 3-7 and $12 \mu \mathrm{m}$. Boundary Layer Meteorology, 18, 131-143.

7. Hagan, D. E., 1989, A based limitation of the split window method for SST retrieval when applied to a wide range of water vapor conditions. Geophysical Research Letters, 16, 815-817.

8. Harris, A. R., and Mason, I. M., 1992, An extension to the split-window technique giving improved atmospheric correction and total water vapor. International Journal of Remote Sensing, 13, 881-892.

9. Kneizys, F. X., Shettle, E. P., Anderson, G. P., Chetwynd, J. H., Gallery, W. O., Selby, J. E. A., and Chough, S. A., 1988, Users guide to LOWTRAN-7. Technical Report AFGL-TR-88-0177.

10. McClain, E. P., 1980, Multiple atmospheric-window techniques for satellite-derived sea surface temperature. Oceanography from Space (J F. R. Grower, Editor), 7385, Plenum, N.Y. U.S.A.

11. McMillin, L. M., 1975, Estimation of sea surface temperature from two infrared window measurements with different absorption. Journal of Geophysical Research, 80, 5113-5117.

12. Prabhakara, C., Dalu, g, and Kunde, V. G., 1974, Estimation of sea surface temperature from remote sensing in the 11 to 13 window region. Journal of Geophysical Research, 79, 5039-5044.

13. Smith, W. L., Rao, P. K., Koffler, P., and Curtis, W. R., 1970, The determination of sea surface temperature from satellite high resolution infrared window radiation measurements. Monthly Weather Review, 98, 604-611.

14. Walton, C. C., 1988, Nonlinear multichannel algorithms for estimating sea surface temperature with AVHRR satellite data. Journal of Applied Meteorology, 27, 115124.

15. Yu, Y., and Barton, I. J., 1994, A non-regression-coefficients method of sea surface temperature retrieval from space. International Journal of Remote Sensing, 15, 1189-1206. 


\section{非迥歸係數方法於AVHRR 資料求取 海溫之改進}

劉振榮郭宗華林唐煌

國立中央大學太空及遙測研究中心

高伯 健

國立中央大學大氣科學研究所

劉崇治

空軍航空技術學校

摘 要

Yu and Barton曾提出一個非迥歸係數方法用以 應用衛星資料求取海面温度, 該方法也普遍地推廣到 多種衛星反演海温的模式, 如MCSST與CPSST模 式。在他們的方法中，需計算雨個紅外窗區頻道相鄰 視場温度變化值的比值, 即 $R_{54}\left(\Delta T_{5} / \Delta T_{4}\right)$, 其中使用 到統計的運算, 因此有時並不適用於眞實的海氧情 況。本研究旨在保有該方法的物理考慮及推導優點, 並改進的計算方法。並使用空間相干法及三點法滤雲 與標定晴空區以獲得更精確的海温分佈。應用本研究 所改良的非迴歸係數方法反演出台灣附近 $10^{0} \times 10^{0}$ 範 圍的海温分佈圖, 並與船測海温及其他三種方法 (Chen, MCSST, CPSST) 所反演的海温比較, 顯示本 方法可獲致 $0.8 \mathrm{~K}$ RMSE及 $0.1 \mathrm{~K}$ bias的精度, 且在雲 污染區有較其他方法更好的表現， 